\title{
Analisis Perencanaan Investasi Jaringan Tenaga Listrik \\ ${ }^{1}$ Dwi Ajiatmo, ${ }^{2}$ Henny Dwijayani \\ ${ }^{1}$ Program Studi Teknik Elektro, Universitas Darul Ulum Jombang 61413 \\ ${ }^{2}$ Program Studi Manajemen, Universitas Darul Ulum Jombang 61413 \\ ${ }^{1}$ ajiatmo@gmail.com, ${ }^{2}$ hennydwija@gmail.com
}

Article Info
Article history:
Received January $12^{\text {th }}, 2020$
Revised January $20^{\text {th }}, 2020$
Accepted February $26^{\text {th }}, 2020$

\section{Keyword:}

Investment

Electricity

Electric Voltage Network

Project evaluation analysis

\begin{abstract}
Electricity is able to make a positive change and contribution to people's lives and wellbeing. This study aims to assess the feasibility of investment in the construction of low voltage electricity networks. The method used with project evaluation analysis is based on financial analysis. The criteria used to analyze activities carried out for 10 years use payback period (PP) analysis, net present value (NPV), internal rate of return (IRR), and profitability index (IP). The results showed that the analysis of investment planning can be carried out with the consequence of the results obtained in the form of not so large returns. PP results show the investment value with the payback period method will Return in the 9th year, while the positive NPV value is still above zero while the IRR value shows the value of $11 \%$ below the social discount rate as well as the IP value showing the value of 0.90 . The feasibility of investment in terms of economic-financial analysis by looking at per criteria shows that investment is still feasible to be carried out with minimal profit levels.
\end{abstract}

Copyright $(2020$ Jurnal JEETech. All rights reserved.

\section{Corresponding Author:}

Dwi Ajiatmo,

Department of electrical engineering, Darul Ulum University,

J1. KH.Abdurrahman Wahid 9A Jombang

Email: ajiatmo@gmail.com
Abstrak - Listrik mampu memberikan perubahan dan kontribusi positif bagi kehidupan serta kesejahteraan masyarakat. Penelitian ini bertujuan untuk menilai kelayakan investasi pembangunan jaringan listrik tegangan rendah. Metode yang digunakan dengan analisis evaluasi proyek berdasar analisis keuangan. Kriteria yang digunakan untuk menganalisis kegiatan yang dilakukan selama 10 tahun menggunakan analisis payback period (PP), net present value (NPV), internal rate of return (IRR) dan index profitability (IP). Hasil penelitian menunjukan bahwa analisis perencanaan investasi yang dilakukan dapat dijalankan dengan konsekuensi hasil yang diperoleh berupa return tidak begitu besar. Hasil PP menunjukan nilai investasi dengan metode payback period akan Kembali pada tahun ke 9, sedangkan nilai NPV positif masih diatas nol sementara nilai IRR menunjukan nilai $11 \%$ dibawah nilai social discount rate demikian juga nilai IP menunjukan nilai 0.90. Kelayakan investasi dari sisi analisis ekonomi-keuangan dengan melihat per kriteria menunjukan bahwa investasi masih layak dilaksanakan dengan tingkat keuntungan yang minim.

\section{Pendahuluan}

Rasio elektrifikasi nasional tahun 2017 tercatat $95.35 \%$, dengan jumlah rumah tangga sebanyak 62,5 juta atau 93,03\% rumah tangga disuplai oleh PT. PLN (Persero). Sementara 1,5 juta atau 2,32\% rumah tangga mendapat listrik off-grid non PT. PLN (Persero) yang dibangun oleh Pemerintah Daerah dan Swasta. Melalui program pra elektrifikasi di daerah terdepan, terluar dan tertinggal (3T) pada tahun 2017, maka lektrifikasi mendapat tambahan $0,02 \%$ sehingga menjadi 95,37\%. Keluarnya Undang-Undang Ketenagalistrikan telah membawa suatu perubahan yang sangat signifikan bagi penyediaan dan pembangunan sistem pembangkit maupun sistem jaringan tenaga listrik. Undang-undang ketenagalistrikan telah membawa peran serta pemerintah daerah maupun swasta dalam ikut serta dalam pengelolaan energi kelistrikan[1][2][3].

Keterbatasan sumber dana dapat diatasi dengan peran serta pemerintah daerah dan swasta dalam menginvestasikan dananya untuk pembangunan pemenuhan jaringan tenaga listrik untuk daerah-daerah yang belum terelektrifikasi. Jaringan baru yang akan dibangun tentunya harus mempunyai koridor kemampuan segi teknis yang harus diperhatikan dan segi ekonomis (pembiayaannya). Kriteria penilaian layak tidaknya suatu investasi yang dilakukan harus melalui proses 
studi kelayakan dan kebijakan investasi yang akan dilakukan. Kebijakan investasi yang dilakukan akan mempengaruhi profitabilitas perusahaan dan berdampak pada nilai perusahaan[4].

Kriteria penilaian proyek dapat dievaluasi dari enam aspek, yaitu[5][6];

1. Aspek teknis, aspek teknis ini meliputi evaluasi tentang input dan output dari barang dan jasa yang akan diperlukan dan diproduksi oleh proyek.

2. Aspek manajerial dan administrasi, aspek manajerial dan administrasi menyangkut kemampuan staff dari pada proyek untuk menjalankan aktivitas administrasi dalam ukuran besar (large scale activities). Keahlian manajemen hanya dapat dievaluasi secara subyektif. Tetapi meskipun demikian, kalau hal ini tidak mendapat perhatian khusus maka banyak kemungkinan terjadinya pengambilan keputusan yang tidak realistis dalam proyek yang direncanakan.

3. Aspek organisasi, aspek organisasi perhatiannya terutama ditujukan pada hubungan antara administrasi proyek dengan bagian administrasi pemerintah lainnya dan untuk melihat apakah hubungan antara masing-masing wewenang dan tanggung jawab diketahui dengan jelas.

4. Aspek komersial, aspek komersial menyangkut penawaran input (barang dan jasa) yang diperlukan proyek, baik waktu membangun proyek maupun pada waktu proyek sudah berproduksi dan menganalisa pemasaran output yang akan diproduksi oleh proyek.

5. Aspek finansial, aspek finansial menyangkut terutama perbandingan antara pengeluaran uang dengan revenue earning dari proyek. Apakah proyek akan terjamin dananya yang diperlukan, apakah proyek itu akan berkembang sedemikian rupa sehingga secara finansial dapat berdiri sendiri.

6. Aspek ekonomi, aspek ekonomi diperhatikan dalam rangka menentukan apakah proyek itu akan memberikan sumbangan atau mempunyai peranan yang positif dalam pembangunan ekonomi seluruhnya. Dalam ilmu mengevaluasi proyek biasanya ditekankan hanya dua macam analisis, yaitu:

a. Analisis finansial, dalam analisis ini proyek dilihat dari sudut badan-badan atau orang-orang yang menanam modalnya dalam proyek atau berkepentingan langsung dalam proyek.

b. Analisa ekonomis, dalam analisis ini proyek dilihat dari sudut perekonomian dari keseluruhan.

Capital budgeting merupakan keseluruhan proses perencanaan dan pengambilan keputusan mengenai pengeluaran dana yang melebihi jangka waktu 1 tahun, dan perusahaan berharap akan memperoleh kembali dana yang tertanam dalam investasi tersebut dalam jangka waktu tertentu yang telah diantisipasi. Capital budgeting merupakan keseluruhan proses perencanaan dan pengambilan keputusan mengenai pengeluaran dana yang melebihi jangka waktu 1 tahun, dan perusahaan berharap akan memperoleh kembali dana yang tertanam dalam investasi tersebut dalam jangka waktu tertentu yang telah diantisipasi[7][8][9].

1. Klasifikasi investasi terdiri dari tiga (a) Replacement (penggantian), investasi replecement adalah untuk penggantian mesin, alat-alat produksi (aktiva tetap) lama maupun baru. Hal ini disebabkan karena mesin atau aktiva tetap tersebut sudah habis umur ekonomisnya atau sudah dimakan mode. (b) Extension invesment (investasi untuk perluasan), investasi untuk perluasan adalah investasi yang dilakukan untuk perluasan, baik pabrik maupun usaha yang mengakibatkan pengeluaran untuk barang-barang dan modal. Masalah yang penting dalam investasi jenis ini adalah menentukan pendapatan dan hasil kembalian dari investasi untuk meningkatkan keuntungan dan nilai perusahaan[4]. (c) New product activities, New product activities adalah dalam katagori ini adalah memproduksi jenis produk baru, dengan kata lain dilakukannya suatu usaha untuk memperbaiki produk yang telah ada. Hal ini tergantung dari strategi investasi yang bersangkutan.

2. Kegunaan cash flow, digunakan untuk menaksir atas penjualan atau kebutuhan pembiayaan proyek dan untuk memaksimalkan profitabilitas dengan menggunakan kas secara efisien. Dalam penggunaan cash flow, bisa dikatakan bahwa cash flow atau aliran kas itu dapat digunakan untuk menilai sekaligus memaksimalkan profitabilitas proyek investasi yang dilakukan dalam perusahaan dalam suatu periode tertentu. Disamping itu aliran kas menunjukan bahwa tidak hanya jumlah keuangan yang dibutuhkan dari bulan ke bulan, dari minggu ke minggu atau hari ke hari dan itu adalah suatu alat yang penting bagi manager keuangan.

\section{A. Tahanan}

Resistansi suatu penghantar ditentukan berdasarkan type penghantar dengan persamaan (1) sebagai berikut[10][11][12][13][14]:

$$
R=\frac{r x L}{A}(\Omega / k m)
$$

Dengan : $\mathrm{r}=$ resistivity konduktor $\left(\Omega \mathrm{mm}^{2} / \mathrm{m}\right)$

$$
\begin{aligned}
& \mathrm{L}=\text { panjang konduktor }(\mathrm{m}) \\
& \mathrm{A}=\text { luas penampang konduktor }\left(\mathrm{mm}^{2}\right)
\end{aligned}
$$

Untuk koreksi resistansi karena adanya perubahan kenaikan suhu keliling dari $\mathrm{t}_{1}$ dan $\mathrm{t}_{2}$, maka dapat digunakan persamaan (2) sebagai berikut: 


$$
R_{2}=R_{1} x \frac{T+t_{2}}{T+t_{1}}(\Omega / K m)
$$

sehingga untuk perubahan nilai resistansi dari suhu $\mathrm{t}_{1}=20^{\circ} \mathrm{C}$ dan $\mathrm{t}_{2}=30^{\circ} \mathrm{C}$, persamaan dapat disederhanakan menjadi:

$$
R_{30}=R_{20} x \frac{T+30}{T+20}(\Omega / K m)
$$

Dengan :

$$
\begin{array}{ll}
\mathrm{R}_{20} & =\text { tahanan pada suhu } 20^{\circ} \mathrm{C}(\Omega / \mathrm{Km}) \\
\mathrm{R}_{30} & =\text { tahanan pada suhu } 30^{\circ} \mathrm{C}(\Omega / \mathrm{Km}) \\
\mathrm{T} & =228 \text { (untuk alumunium hard drawn) }
\end{array}
$$

\section{B. Reaktansi}

Untuk mencari nilai reaktansi kabel pilin almunium,maka digunakan persamaan (4) sebagai berikut :

$$
x=0.1447 x \log \frac{G M D}{G M R}(\Omega / k m)
$$

Dengan :

$$
\begin{aligned}
\text { GMD } & =\text { Geomertic Mean Distance } \\
\text { GMR } & =\text { Geometric Mean Radius }
\end{aligned}
$$

Untuk GMD besarnya ditentukan oleh konfigurasi jarak antar saluran, sehingga persamaannya :

$$
G M D=\sqrt[3]{a b x b c x a c}(\mathrm{~mm})
$$

Untuk memudahkan pengukuran dan perhitungan, maka konfigurasi dari penghantaran kabel pilin diasumsikan membentuk persegi empat.

\section{Impedansi}

Impedansi (Z) adalah terdiri dari bagian nyata, yaitu tahanan (R) dan bagian semu, yaiyu reaktansi (X). Untuk suatu impedansi yang berhubungan dengan pergeseran sudut daya maka dapat menggunakan persamaan sebagai berikut :

$$
Z=r \operatorname{Cos} \theta+j x \operatorname{Sin} \theta(\Omega / k m)
$$

Dengan :

$$
\begin{array}{ll}
\mathrm{r} & =\text { resistansi }(\Omega / \mathrm{km}) \\
\mathrm{x} & =\text { reaktansi }(\Omega / \mathrm{km}) \\
\operatorname{Cos} \theta & =\text { sudut daya, dalam derajat }
\end{array}
$$

\section{Drop Tegangan}

Hubungan antara besar beban yang ada sekarang dan yang akan datang dipengaruhi langsung oleh faktor pertumbuhan beban. Hubungan tersebut dapat dinyatakan dalam persamaan sebagai beriklut:

$$
\begin{gathered}
K W_{t}=K W_{p} \cdot(1+G)^{t} \\
K W_{f}=K W_{p} \cdot(1+G)^{n}
\end{gathered}
$$

dimana;

$\mathrm{KW}_{\mathrm{p}} \quad$ = besar beban yang ada sekarang $(\mathrm{KW})$.

$\mathrm{KW}_{\mathrm{f}} \quad=$ besar beban setelah n-tahun mendatang $(\mathrm{KW})$

$\mathrm{KW}_{\mathrm{t}}=$ besar beban setelah $\mathrm{t}$-tahun mendatang $(\mathrm{KW})$

$\mathrm{G}=$ besaran pertumbuhan beban dalam desimal

$\mathrm{n}=$ jumlah tahun operasi yang direncanakan

$$
V D=\frac{(\mathrm{KW}) \cdot(\mathrm{R} \operatorname{Cos} \theta)+\mathrm{X} \operatorname{Sin} \theta) \cdot(220)}{(K V)^{2} \cdot(\operatorname{Cos} \theta) \cdot \varphi \cdot(1000)}
$$

Pada umumnya perhitungan voltage drop (jatuh tegangan) pada kawat penghantar jaringan besarnya dihitung persatuan jarak, dalam hal ini adalah per kilo-meter, maka bila dihitung dalam persatuan jarak kilo-meter, persamaan menjadi:

$$
V D=\frac{(\mathrm{KW}) \cdot(\mathrm{R} \operatorname{Cos} \theta+\mathrm{X} \operatorname{Sin} \theta) \cdot(S) \cdot(220)}{(K V)^{2} \cdot(\operatorname{Cos} \theta) \cdot \varphi \cdot(1000)}
$$

dimana;

$$
\begin{aligned}
& \mathrm{R}=\text { Tahanan atau resistansi kawat penghantar }(\Omega / \text { phase } / \mathrm{KM}) \\
& \mathrm{X}=\text { Reaktansi kawat penhantar }(\Omega / \text { phase/KM }) \\
& \mathrm{S}=\begin{array}{l}
\text { Jarak titik cabang yang diperhitungkan pada jaringan } \\
\text { tersebut }(\mathrm{Km})
\end{array}
\end{aligned}
$$

Persamaan untuk mencari biaya total tahunan dapat dituliskan sebagai berikut:

$$
T=C . A+\frac{K W^{2}}{(K V)^{2} \cdot(\operatorname{Cos} \theta)^{2} \cdot P} . R . J
$$

persamaan (11) dan (10) inilah yang dipergunakan untuk menghitung keadaan jaringan.

\section{E. Persamaan untuk mencari faktor pertumbuhan besar beban}

Hubungan antara besar beban yang ada sekarang dan yang akan datang dipengaruhi langsung oleh faktor pertumbuhan beban. Hubungan tersebut dapat dinyatakan dalam persamaan sebagai beriklut:

$$
\begin{aligned}
& K W_{t}=K W_{p}(1+G)^{t} \\
& K W_{f}=K W_{p}(1+G)^{n}
\end{aligned}
$$

Dengan:

$\mathrm{KW}_{\mathrm{p}}=$ Besar beban yang ada sekarang $(\mathrm{KW})$

$\mathrm{KW}_{\mathrm{f}}=$ Besar beban setelah n-tahun mendatang $(\mathrm{KW})$

$\mathrm{KW}_{\mathrm{t}}=$ Besar beban setelah t-tahun mendatang $(\mathrm{KW})$

$\mathrm{G}=$ Besar pertumbuhan beban dalam decimal

$\mathrm{n} \quad=$ Jumlah tahun operasi yang direncanakan 


\section{METODE PENELITIAN}

Untuk menghitung tingkat kelayakan investasi dan tingkat pengembalian modal dipergunakan metode sebagai berikut[6][15]:

A. Metode pay back period (PP)

Persamaan untuk mencari nilai besar payback period adalah;

$$
P P=\frac{\text { Nilai Investasi }}{\text { Kas Masuk Bersih }} x 1 \text { tahun }
$$

B. Metode net present value (NPV)

Bahwa metode Net Present Value merupakan metode yang menghitung selisih antara nilai sekarang investasi dengan nilai sekarang penerimaan-penerimaan kas bersih dimasa yang akan datang.

$$
N P V=\sum_{t=0}^{n} \frac{B_{t}-C_{t}-K_{t}}{(1+i)^{t}}
$$

\section{Metode internal rate return (IRR)}

Bahwa internal rate of return (IRR) didefinisikan sebagai tingkat bunga yang akan menjadikan jumlah nilai sekarang dari proses yang diharapkan akan diterima (present value future proceeds) sama dengan jumlah nilai sekarang dari pengeluaran modal (present value of capital outlays).

$$
I R R=\sum_{t=1}^{n} \frac{B_{t}-C_{t}-k_{t}}{(1+r)^{t}}
$$

D. Profitability ratio/index profitability $(P R / I P)$

$$
I P=\frac{\sum_{t=1}^{n} \frac{b_{t}-c_{t}}{(1+i)^{r}}}{\sum_{t=1}^{n} \frac{k_{t}}{(1+i)^{r}}}
$$

dengan ;

$\mathrm{B}_{\mathrm{t}}=$ Penerimaan pada tahun ke 1 sampai tahun ke $\mathrm{n}$

$\mathrm{K}_{\mathrm{t}} \quad=$ Kapital yang digunakan pada periode investasi

$\mathrm{C}_{\mathrm{t}}=$ Pengeluaran pada tahun ke 1 sampai tahun ke $\mathrm{n}$

i $\quad=$ Tingkat Discount rate

$\mathrm{r} \quad=$ Internal rate of return.
Tabel 1. Data Parameter

\begin{tabular}{|r|l|r|}
\hline No & \multicolumn{1}{|c|}{ Parameter } & \multicolumn{1}{|c|}{ Value } \\
\hline 1 & Tahanan & $0,430 \Omega / \mathrm{km}$ \\
2 & Reaktansi & $0,081 \Omega / \mathrm{km}$ \\
3 & Impedansi & $0,413 \Omega / \mathrm{km}$ \\
4 & Drop Tegangan & $0,9 \mathrm{Volt}$ \\
5 & Faktor drop tegangan & 0,025 \\
6 & Beban setelah n-tahun (KW) & $13,502 \mathrm{Kw}$ \\
7 & Calon jumlah pelanggan & 500 \\
8 & Pemakaian energi pelanggan & $30 \mathrm{kw} / \mathrm{tahun}$ \\
9 & Asumsi faktor pertumbuhan beban & $8 \%$ \\
10 & Masa investasi & $10 \mathrm{tahun}$ \\
11 & Cost of capital (COC) & $12 \%$ \\
12 & Daya terpasang & $900 \mathrm{VA}$ \\
13 & Penghantar yang digunakan & $3 \varphi \mathrm{x} 70 \mathrm{~mm}^{2}+1 \times 50 \mathrm{~mm}{ }^{2}$ \\
\hline
\end{tabular}

Hasil analisis perhitungan dengan software program

\begin{tabular}{|c|c|c|c|c|c|c|c|c|c|c|c|}
\hline Tahun & & 1 & ? & 3 & 4 & j & o & 1 & 8 & 9 & \\
\hline hestasi aningan & 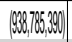 & & & & & & & & & & \\
\hline \multicolumn{12}{|l|}{ Nássia } \\
\hline Lumat Peanganal & & 50 & 540 & 580 & 600 & 600 & 736 & $7 \%$ & 807 & 925 & \\
\hline 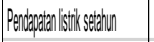 & & 188, 100,00 & $107,78,000$ & $\mid 84,47,9040$ & $109,10,460]$ & $216,093,915$ & 20230,700 & 20180804800 & $20,056,677$ & 22020201060 & 360,026202 \\
\hline 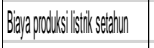 & & 9, $, 02,00$ & 10,514,800 & $|10,656,184|$ & $17,28,790$ & $126,607,106$ & $136,736,67$ & 177, $74,2,24$ & $159,480,460$ & $17227,5,565$ & 186,0727,371 \\
\hline 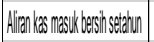 & 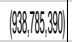 & 65,040,00 & 70248,200 & $75,026,656$ & $81,93,600$ & $88,466,202$ & $95,560,080$ & 192:20:36 & $111,467,100$ & $\mid 20,280,501$ & 130,015,206 \\
\hline Pajpaxk & $(888,763230)$ & $|1877,765,300|$ & 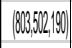 & 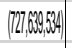 & $(065,7,7,8060$ & $|57,21,1,604|$ & $\mid 460,66,560$ & $(158,4,6,6020$ & 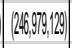 & $\mid 126,594,6280$ & $3,40,032$ \\
\hline \multicolumn{12}{|l|}{ 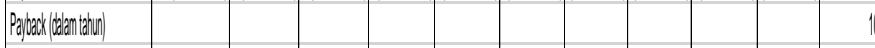 } \\
\hline NPV (tate) & & 0.0 & 0.00 & 0.71 & 0.44 & $0.5]$ & 0.51 & 0.5 & 0.4 & 0.86 & 0.34 \\
\hline NPV (alian |lase) & $(898,7635020)$ & $5807,1,200$ & $55,099,49$ & $53,997,50$ & 52010,151 & 50,20,47 & $48,46,252$ & 46,687,100 & 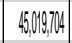 & 4841,1580 & $41,806,1,54$ \\
\hline NPY kumalifi & $(898,763230)$ & $|8007,713,960|$ & $(864,76,512)$ & $(77071899292$ & 7786999,96 & $|(608,44,480)|$ & $(020,042,216$ & $(573,33,116$ & {$[528,379,40]$} & 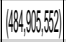 & $\mid(46,0,4,1$ \\
\hline 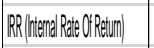 & $14 \%$ & & & & & & & & & & \\
\hline Inets Pritidatilitas & 0.0 & & & & & & & & & & \\
\hline Retun Ch mresiment (BO) & $7 \%$ & & & & & & & & & & \\
\hline
\end{tabular}
Microsoft excel diperoleh seperti pada table 2 dibawah:

Tabel 2. Analisis Perencanaan Investasi Jaringan Tenaga Listrik

Sumber : Data diolah

\section{Hasil dan Pembahasan}

Berdasar data sistem peralatan dan data jaringan tenaga listrik, maka diperoleh data sebagaimana tabel 1. Dalam menganalisis kelayakan proyek dilakukan analisis menggunakan software microsoft excel 2019, 
Hasil olah data pada analisis perencanaan investasi jaringan tenaga listrik sebagai berikut:

1. Payback Period (PP) nilai PP sebesar 9 tahun sedangkan periode investasi 10 tahun, maka investasi ini layak dijalankan karena PP < dari usia proyek.

2. Net Present Value (NPV) menunjukan nilai NPV table positif tidak lebih dari +1 artinya proyek dapat dijalankan.

3. Nilai pada olah data diperoleh IRR $11 \%$ lebih kecil dari nilai COC yang sebesar $12 \%$, padahal untuk layak investasi nilai IRR harus lebih besar dari nilai COC.

4. Nilai indek profitabilitas (IP) dari olah data daya $900 \mathrm{VA}$, nilai IP sebesar 0,9. Investasi layak apabila nilai IP $>1$.

5. Nilai return on investment (ROI) dari data diolah sebesar $7 \%$, menunjukan keuntungan yang diperoleh dari investasi sebesar $7 \%$.

Berdasarkan analisis proyek teknis dan ekonomi maka proyek dapat dijalankan dengan return yang minim $7 \%$.

\section{KESIMPULAN} berikut

Hasil analisis evaluasi proyek dapat disimpulkan sebagai

1. Investasi jaringan tegangan rendah

a. Metode payback period $(\mathrm{PP})=9$ tahun, artinya nilai investasi akan Kembali pada tahun ke 9 dari investasi yang direncanakan selama 10 tahun.

b. Metode Net Present Value $(\mathrm{NPV})=$ nilai positif dibawah 1.

c. Metode Internal rate of return $($ IRR) $=11 \%<12 \%$ (COC) nilai lebih kecil.

d. Metode Indek Profitabilitas (IP) $=0,90<1$ untuk kemampuan menghasilkan laba harus diatas 1 .

e. Metode return on investment $(\mathrm{ROI})=7 \%$ return yang dihasilkan dari investasi.

2. Hasil PP menunjukan nilai investasi dengan metode payback period akan Kembali pada tahun ke 9, sedangkan nilai NPV positif masih diatas nol sementara nilai IRR menunjukan nilai $11 \%$ dibawah nilai social discount rate demikian juga nilai IP menunjukan nilai 0.90. Kelayakan investasi dari sisi analisis ekonomikeuangan dengan melihat per kriteria menunjukan bahwa investasi masih layak dilaksanakan dengan tingkat keuntungan yang minim. Analisis proyek/ perencanaan investasi yang dilakukan dapat dijalankan dengan konsekuensi hasil yang diperoleh berupa return tidak begitu besar.

\section{DAFTAR PUSTAKA}

[1] T. K. K. ESDM, "Menuju Rasio Elektrifikasi 99 Persen pada 2019," http://ebtke.esdm.go.id, 2018. [Online].

Available: http://ebtke.esdm.go.id/post/2018/04/27/1945/menuju. rasio.elektrifikasi.99.persen.pada.2019.

[2] D. Ajiatmo and P. H. Sasongko, "Estimasi biaya minimal pembangunan jaringan tegangan menengah sistem tenaga listrik," Gadjah Mada, 2004.

[3] H. Dwijayani, "Analisis Rasio Likuiditas Dan Solvabilitas Kinerja Keuangan PT PLN (Persero)," Econ. Bisnis Account., vol. 2, no. 7, pp. 169-180, 2015.

[4] H. Dwijayani, Surachman, Sumiati, and H. Djuwahir, "The Influence of The Investment Policy and Information Asymmetry," Int. J. Econ. Perspect., vol. 11, no. 3, pp. 2036-2042, 2017.

[5] Kadariah, L. Karlina, and C. Gray, Pengantar Evaluasi Proyek. Jakarta: Lembaga Penerbit Fekon UI, 1999.

[6] Jumingan, Studi Kelayakan Bisnis, 1st ed. Jakarta: Bumi Aksara, 2009.

[7] F. Weston J, T. E. Copeland, J. Wasana, and Kirbrandoko, Manajemen Keuangan, Jilid 2. Jakarta: Binarupa Aksara, 1992.

[8] K. Subramanyam and J. J. Wild, Analisis Laporan Keuangan, 10th ed. Jakarta: Salemba Empat, 2010.

[9] Kasmir, Analisis Laporan Keuangan, 2nd ed. Jakarta: Rajawali, 2009.

[10] H. Sufitrihansyah, M. Ali R., D. Ajiatmo, and M. Ali, "Penggunaan Binary Particle Swarm Optimization untuk Rekonfigurasi Jaringan Tenaga Listrik pada Penyulang Meri," Prosiding-1 Semin. Nas. Foertei7 -1 2018, vol. 1, no. 1, pp. 134-138, 2018.

[11] D. Ajiatmo and A. H. . Wigantoro, "Kajian Mencari Alteratif Keandalan Sistem Kelistrikan dan Efisiensi Jaringan Saluran Udara Tegangan Menengah (Studi Kasus: PT PLN (Persero) Area Situbondo),' J. Intake, vol. 4, no. 1, pp. 50-62, 2013.

[12] Rukslin, Muhlasin, A. Raikhani, and D. Ajiatmo, "Analisa Perencanaan Trafo Sisipan T. 166 Pada Jaringan Distribusi T. 92 di Ds. Selorejo Kecamatan Mojoagung Kabupaten Jombang," J. Intake, vol. 5, no. 2, pp. 53-67, 2014. 
[13] A. Rodgers, "System Planning Guide, Construction Work Plans," United States Department of Agriculture Rural Utilities Service, 1993. [Online]. Available: https://www.rd.usda.gov/files/UEP_Bulletin_1724D101B.htm. [Accessed: 02-Aug-2020].

[14] PT. PLN (Persero), Spesifikasi Desain untuk Jaringan Tegangan Menengah (JTM) dan Jaringan Tegangan
Rendah (JTR). Jakarta: Departemen Pekerjaan Umum dan Tenaga Listrik, 1987.

[15] M. Pudjosumarto, Evaluasi Proyek, 2nd ed. Yogyakarta: Liberty, 1991. 